\title{
KAJIAN SASTRA BANDINGAN NOVEL SALAH ASUHAN DENGAN NOVEL LAYLA MAJNUN: Pendekatan Psikologi Sastra
}

\author{
Firdauzi Nur Sita ${ }^{1}$, Hana Septiana Jamal ${ }^{2}$, Dian Hartati ${ }^{3}$ \\ Universitas Singaperbangsa Karawang \\ 1710631080063@student.unsika.ac.id ${ }^{1}, 1710631080071 @$ student.unsika.ac.id ${ }^{2}$, \\ dian.hartati@,fkip.unsika.ac.id ${ }^{3}$
}

\begin{abstract}
ABSTRAK
Sastra lahir dari masyarakat, kemudian besar, dan berkembang di masyarakat. Sastra bukan hanya dinikmati dari keindahannya saja, bentuknya, isinya, pentasnya, alunan-alunan yang mengirinya. Melainkan sastra dapat meninjau seberapa jauh manusia berekspresi, melihat dan merasakan kesamaan dan perbedaan sudut pandang, dan makna sastra itu sendiri tiada berbatas zaman, serta melibatkan segala macam ilmu. Sastra Bandingan merupakan cabang ilmu sastra yang mengkaji karya sastra dalam beragam bentuk, fungsi, dan makna. Artikel ini mencoba meninjau dari aspek Psikologi Sastra akan dua karya sastra yang dibandingkan yakni novel yang berjudul "Salah Asuhan" karya Abdul Moeis dengan novel yang berjudul "Layla Majnun" karya Syaikh Nizami. Teori psikologi yang digunakan ialah teori Sigmund Freud (1923), ada tiga unsur kepribadian dalam teori psikoanalisis yaitu Id, Ego, dan Superego. Id merupakan sistem kepribadian yang asli, dibawa sejak lahir. Saat dilahirkan, id berisi semua aspek psikologi yang diturunkan seperti insting, impuls, dan drives. Dari id ini kemudian muncul ego dan superego. Ego beroperasi mengikuti prinsip realita. Sedangkan, superego berkaitan dengan kekuatan moral dan etika dari kepribadian yang beroperasi, memakai prinsip idealistik, sebagai lawan dari id dan ego. Tinjauan ini dimaksudkan guna meneliti kejiwaan atau psikologis tokoh utama dari kedua novel tersebut. Metode yang digunakan dalam penelitian ini adalah analisis deskriptif. Populasi dalam penelitian ini adalah dua novel di di atas. Sampel di sini adalah ujaran narasi ataupun ujaran dari tokoh kedua novel tersebut. Hasil penelitian ini berupa ujaran narasi atau ujaran tokoh utama yang berkenaan dengan id, ego, dan superego pada kedua novel tersebut yang kemudian dideskripsikan dengan interpretasi.
\end{abstract}


Kata Kunci: kajian bandingan, psikologi sastra, salah asuhan, layla majnun

ABSTRACT

PENDAHULUA $\mathbf{N}$
Literature was born from society, then grew up, and developed in society. Literature is not only enjoyed from its beauty, but about its form, content, stage, strains that come with it. However, literature can investigate how far humans express, see and feel the similarities and differences in viewpoints, and meanings of literature itself that has no boundaries of time, and involves all kinds of knowledge. Comparative Literature is a branch of literature that examines literary works in various forms, functions and meanings. This article tries to investigate from the aspect of literary psychology of the two literary works being compared, namely the novel entitled "Salah Asuhan" by Abdul Moeis and the novel entitled "Layla Majnun" by Syaikh Nizami. The psychological theory used is the theory, namely Id, Ego, Superego. The Id is the original personality system, carried from birth. At birth, the id contains all inherited aspects of psychology such as instinct, impulses, and drives. From this emerge the ego operates according to the principles of reality. Meanwhile, the superego is concerned with the moral and ethical forces of the personality thet operate, using idealistic priinciples, as opposed to the id and ego. This article is to investigate the psychiatric or psychological characteristics the main character of the two novels. The methods is used a descriptive analysis. The population in this this study are the two novels mentioned above. The sample here is the narratives speech or utterances of the characters of the two novels. The results of this study are in the form of narrative utterances or main charater utterances regarding id, ego, and superego in the novels which are then described by interpretation.

Keywords: comparative study, literature psychology, salah asuhan, layla majnun

Karya sastra lahir dan hidup di tengah masyarakat. Perkembangan isi karya sastra mengikuti zaman dilahirkannya. Pada tahun 1920, dikenal dengan angkatan "Balai Pustaka", banyak karya sastra yang dilahirkan untuk pertama kali mengangkat kisah modern awal. Novel Salah Asuhan terbit 
pertama kali tahun 1928 dan menjadi bagian angkatan "Balai Pustaka". Rosidi (2017: 36) mengungkapkan bahwa karya sastra lainnya yang terkenal pada saat itu ialah Sitti Nurbaya karya Marah Rusli (1922) dan Azab dan Sengsara karya Merari Siregar (1920). Banyak dari pengarang angkatan "Balai Pustaka" mengangkat kisah yang sama dan menjadi bagian dari tradisi dan adat istiadat masyarakat. Tema pokok tersebut ialah kasih tak sampai. Kasih tak sampai merupakan penyiksaan terhadap hati yang hadir tanpa alasan. Kecintaan terhadap seseorang, tidak dapat dipungkiri keberadaannya dan tidak dapat direncanakan pula kehadirannya. Salah Asuhan karya Abdoel Moeis, penggambaran kasih tak sampai yang dirasakan oleh tokoh Hanafi dan tokoh Corrie karena perbedaan kedudukan warga negara. Cerita tersebut hadir ketika Indonesia belum lahir dan masih dalam jajahan Belanda dengan nama Hindia Belanda serta bahasa yang digunakan ialah bahasa Melayu.

Kasih tak sampai yang disajikan dalam novel Salah Asuhan, juga dirasakan dalam novel termasyhur Sitti Nurbaya karya Marah Rusli. Kasih tak sampai yang dialami tokoh dalam novel Sitti Nurbaya akibat terjadinya perjodohan karena keluarga yang tidak mampu membayar hutang. Begitu juga dengan novel angkatan "Balai Pustaka" lainnya yang banyak mengangkat tema pokok kasih tak sampai dengan berbagai penderitaan yang dialami tokoh utama. Bahkan sampai pada saat ini, banyak karya sastra yang juga lahir dengan menyajikan tema pokok kasih tak sampai, seperti novel Wedding Agreement karya Mia Chuz (2018), dan Perfect Husband karya Indah Riyana (2016). Kedua novel tersebut menjadi terkenal setelah diadaptasikan ke dalam sebuah film. Namun, yang membedakan tema pokok kasih tak sampai yang dilahirkan oleh pengarang angakatan "Balai Pustaka" dengan saat ini, yaitu akhir yang tidak bahagia dan banyaknya penderitaan yang dialami para tokoh di dalamnya, sangat berbeda dengan akhir yang bahagia sealu disajikan dalam novel pengarang saat ini.

Tema pokok kasih tak sampai yang disajikan dalam novel Salah Asuhan, ternyata juga hadir dalam kesusastraan dunia. Salah satu cerita yang terkenal yaitu Layla Majnun. Memiliki judul asli Leyli o Majnun karya Nizami, yang awalnya merupakan sajak anekdot, dan kemudian dikembangkan menjadi sajak naratif. Layla Majnun mengisahkan tokoh pemuda bernama Qays yang jatuh cinta dengan gadis bernama Layla. Cinta mereka ditentang karena perbedaan golongan masyarakat yang mementingkan kedudukan harta keluarga. Obsesi cinta Qays pada 
Layla membuatnya menjadi gila. Novel Layla Majnun sekilas mirip dengan cerita yang terkenal berasal dari Inggris, Romeo dan Juliet karya Shakespeare. Namun, umur cerita Layla Majnun lebih lama dibandingkan Romeo dan Juliet. Tidak hanya itu, novel milik Shakespeare tersebut juga memiliki tema pokok kasih tak sampai, dengan konflik keluarga tokoh Romeo dan tokoh Juliet bermusuhan. Begitu banyak karya sastra yang mengangkat tema pokok kasih tak sampai, dengan kesamaan cerita Salah Asuhan dengan Layla Majnun menjadi satu hal yang perlu dikaji lebih luas agar dapat diketahui perbedaan di dalamnya.

Karya sastra tak akan lepas dari pengaruh zaman dan menjadi catatan tak langsung dalam menandai zaman. Karya sastra pun menjadi cerminan suatu bangsa, agama, budaya, ras, ideologi, keadaan, sistem, dan hal-hal lainnya. Karya sastra pula menjadi cerminan sosial dan psikologi serta gambaran kehidupan. Melihat pada sisi budaya novel Salah Asuhan yang berasal dari tanah Melayu tentunya dipengaruhi oleh budaya Eropa, dan pribumi Melayu yang memegang erat tradisi adat sebenar adat atau adat yang tidak bisa diubah karena ketentuan agama, adat yang diadatkan atau adat yang dibuat oleh penguasa, dan adat teradat merupakan konsensus yang ditetapkan bersama yang dijadikan sebagai pedoman dalam setiap lini kehidupan di masyarakat dan penentuan sikap dalam menghadapi sebuah peristiwa dan masalah lingkungan. Budaya Belanda begitu kental dalam novel Salah Asuhan yang mana secara general diklasifikasikan pada budaya kolonialisme dan menjunjung marxisme. Dari sanalah cerita mengenai cinta bertepuk sebelah tangan dan cinta tidak direstui dilatarbelakangi, karena bangsa asing merasa dirinya lebih segalanya dibanding bangsa pribumi. Sisi budaya pada novel Layla Majnun yang berasal dari tanah Arab terbagi pada dua masa, masa pra-Islam dan masa masuknya dan berkembang serta tumbuhnya Islam. Budaya bangsa Arab yang sebenarnya memiliki kesamaan motif yakni mesti sederajat atau jika kaum lelaki mesti satu tingkat di atas derajat sang wanita. Hal itu melatarbelakangi kasih tak sampai dalam cerita pada novel tersebut.

Membandingankan kedua karya sastra novel tersebut dilakukan dengan tinjauan pendekatan teori psikologi sastra hal ini guna menggali kejiwaan tokoh-tokoh yang ada di dalamnya. Sejalan dengan pandangan Ratna (2015: 343), yang mengungkapkan bahwa psikologi sastra memberikan perhatian pada unsur-unsur kejiwaan tokoh fiksi dalam karya sastra. Analisis kepribadian tersebut berlandaskan struktur kepribadian 
menurut Freud yang dijelaskan dalam Minderop (2011: 21-23), bahwa terdapat tiga pembagian psikis manusia, yaitu $i d$, ego, dan superego. Id merupakan energi psikis dan naluri yang menekan manusia agar memenuhi kebutuhan dasar. Ego merupakan pimpinan utama dalam kepribadian, ego yang membuat keputusan terhadap kesulitan yang dihadapi dirinya sendiri. Sedangkan superego mengacu pada moral dalam kepribadian, yang mampu membedakan baik buruknya.

METODE

Penelitian ini mengangkat dua karya sastra yang akan dibandingkan dengan kajian psikologi dan menggunakan pendekatan sastra bandingan komparatif. Endraswara (2014: 175), mengungkapkan bahwa sastra bandingan komparatif yakni upaya membandingkan dua karya sastra atau lebih dari suatu negara dengan negara lain. Bagaimana reputasi pengarang juga dapat terlihat dari bandingan ini. Pasang surut reputasi pengarang dapat ditunjukkan oleh sastra bandingan.

Mengkaji dengan kajian psikologi sastra merupakan kajian sastra yang memandang karya sasra sebagai aktivitas kejiwaan (Endraswara, 2014: 96). Penelitian ini berfokus pada penggalian kejiwaan dari kedua pengarang itu sendiri, tokoh yang ada di dalamnya, dan para pembaca sekalian. Kajian bandingan psikologi sastra dimaksudkan mencari bagaimana kejiwaan dari pada kedua pengarang, tokoh-tokoh yang ada di dalamnya, dan para pembaca sekalian yang memiliki kesamaan. Padahal, terdapat perbedaan masa dan geografis yang mana membuat bahasa, ras, ideologi, dan budaya yang berbeda dari kedua novel ini membuat sisi kejiwaan para tokoh di dalamnya berbeda.

Sumber data dalam penelitian ini adalah novel Salah Asuhan karya Abdoel Moeis yang diterbitkan oleh Balai Pustaka (1928) dan novel Layla Majnun karya Syaikh Nazami Ganjavi yang diterbitkan oleh penerbit Narasi. Data yang dijadikan objek dalam penelitian ini adalah tokoh dan penokohan dari kedua novel tersebut, dan pembaca dalam menanggapi kedua novel tersebut. Pengumpulan data dalam penelitian ini dengan mencari aspek psikologi kepribaian dalam kedua karya satra yaitu aspek $i d$, ego, dan super ego berdasarkan teori psikoanalisis Freud yang dikemukakan oleh Minderop. Proses analisis data dalam penelitian ini adalah teknik pustaka, teknik simak, dan catat. Langkah-langkah penelitian dengan pendekatan psikologi sastra sesuai dengan yang diungkapkan Endraswara (2008: 89), langkah pertama ialah memahami teori yang berkaitan dengan psikologi 
sastra. Kedua, menentukan karya sastra dan teori psikologi yang cocok dengan karya sastra. Terakhir, yaitu penyajian data. Teknik penyajian data yang digunakan ialah metode informal.

PEMBAHASA $\mathbf{N}$
Dalam sebuah cerita, tokoh-tokoh baik tokoh utama atau tokoh bawaan pastinya memiliki kepribadian yang ada pada dirinya. Novel Salah Asuhan karya Abdoel Moeis merupakan novel yang begitu kuat dalam memvisualisasikan kepribadian dari sang tokoh utama yakni Hanafi dan Corrie dibandingkan dengan novel Layla Majnun karya Syaikh Nizami merupakan novel yang begitu kuat dalam menggambarkan kepribadian dari sang tokoh utama Qays dan Layla. Kepribadian yang ada dalam kedua tokoh tersebut dikupas dengan tinjauan psikologi sastra melalui teori Freud, yaitu id, ego, dan superego. Hasil penelitian berupa data deskriptif yaitu kutipan pada novel beserta penjelasannya. Berikut ini klasifikasi aspek kepribadian yang dimiliki oleh tokoh utama dalam Novel Salah Asuhan karya Abdoel Moeis dan novel Layla Majnun karya Syaikh Nizami.

\section{Psikoanalisis Tokoh dalam Novel Salah Asuhan Karya Abdoel Moeis}

Tokoh utama laki-laki dalam novel Salah Asuhan yaitu Hanafi, memiliki psikoanalisis sebagai berikut.

\section{a. Id}

Aspek id yang terdapat dalam tokoh Hanafi semasa muda atau di awal cerita, yaitu Hanafi yang semasa kanak-kanak erat dengan bangsa Belanda, sebab ia bersekolah di betawi, dan di sekolah Belanda sudah barang tentu pandangan Hanafi dan gaya hidup Hanafi sudah kebarat-barat dan seperti orang asing, sebab pula banyak bergaul dengan orang Barat. Puncaknya, ketika Hanafi bertemu dengan Corrie perempuan berbangsa asing atau barat (Perancis) atau bangsa penjajah yang dihormati dan mempunyai derajat yang tinggi serta bangsa yang datang dan dipertuan, dan Hanafi lantas menaruh hati pada perempuan tersebut. Hal tersebut terlihat dalam kutipan sebagai berikut.

"Sejurus lamanya Hanafi memandang dengan hati berahi kepada nona yang cantikitu, yang dengan senyumnya seolah-olah hendak menunjukkan dan melemahkan hati manusia yang sekeras-kerasnya" (hlm. 5) 
Kutipan tersebut menunjukkan penggambaran ketika Hanafi mulai menaruh hati pada Corrie dan nalurinya semakin menjadi saat Corrie yang amat molek parasnya yang hari itu mengenakan baju tenis dari benang wol merah tua dan rambutnya terurai dengan sikapnya yang dapat membawa hanyut setiap lelaki. Hal tersebut terlihat dalam kutipan sebagai berikut.

"Setelah ia memandang sejurus lamanya pada mata gadis yang sedang membujuknya itu, maka digenggamnyalah dengan kelima jarinya tangan Corrie yang sedang meraba tangannya itu, diciumnya punggung tangan si gadis itu” (hlm. 6)

Kutipan tersebut menunjukkan id Hanafi semakin menaruh hati ketika melihat Corrie yang molek berpenampilan menarik dan menawan setiap lelaki. Hasrat Hanafi pada Corrie semakin membara dan sudah sulit dibendungnya. Hal tersebut terlihat dalam kutipan sebagai berikut.

"Hanafi memperhatikan benar keadaan Corrie yang demikian itu. Maka tak kuatlah ia menahan hatinya lagi, dan tidak disengaja-sengaja, sekonyong-konyong kedua belah tangannya sudah memeluk pinggang Corrie, dan sambil menekan dada gadis itu ke dadanya, diciumnyalah Corrie berkali-kali pada bibirnya, matanya, pada keningnya dan pipinya" (hlm. 46)

Kutipan di atas menunjukkan bahwasanya hasrat Hanafi yang benar-benar mencintai dan menginginkan Corrie. Ketika Corrie memutuskan untuk pergi dari kehidupan Hanafi dan membuat hati Hanafi hancur seketika. Hal tersebut dapat dilihat dalam kutipan sebagai berikut.

\section{b. Ego}

Sebagai manusia biasa Hanafi pula memiliki ego dalam dirinya. Ego tersebut nampak ketika Hanafi menolak perjodohan dengan perempuan minang bernama Rapiah sebagai bayar budi, dan bayar utang atas segala biaya sekolahnya di Betawi dulu. Hal tersebut dapat dilihat dalam kutipan sebagai berikut.

"Jika mereka menunggu piutang, apalagi Engku Sutan Batuah, haruslah mereka menerima kuangsur dengan gajiku. Bukankah tidak kuminta berutang itu kepada 
mereka dahulu?

Sekarang fasal beristri. Apakah guna bunda menyekolahkan daku bila bunda hendak mengadu-adu juga dengan anak negeri kita? Mana rupanya anak negeri kita yang sepadan dengan aku pengetahuannya?" (hlm 31-32)

Dari kutipan di atas jelaslah penolakan Hanafi terhadap perjodohan dengan perempuan Minangkabau sebagai bayar budi dan piutang uang ibundanya semasa menyekolahkannya di Betawi. Hanafi enggan beristri dengan perempuan dari negeri sendiri, yang mana pergaulan dan sekolahnya yang tinggi membuat Hanafi memiliki kehendak agar istrinya pun sepadan dengannya dari segi pengetahuan. Tentu juga, hal ini sebagai penguat bahwasanya Hanafi menginginkan Corrie untuk diperistri karena barang jelas Corrie sepadan dengannya. Akan tetapi angan tetaplah angan, Corrie sudah memutuskan untuk melupakanya dengan berkirim surat dan memintanya untuk memutuskan tali hubungan mereka.

Hanafi berkirim pesan kepada ibunya yang sebenarnya dialamatkan pada Rapiah. Pesan ini dimaksudkan menyudahi hubungan antara dirinya dengan Rapiah, istrinya. Hal tersebut dapat terlihat dalam kutipan penggalan surat berikut.

"Ibu yang tercinta!

Sesungguhnya surat ini haruslah kualamatkan kepada Rapiah, tapi karena perempuan itu kuperoleh dari Ibu, kepada Ibu pulalah ia hendak kupulangkan." (hlm. 132)

Kutipan dari penggalan surat di atas jelaslah menunjukkan ego Hanafi yang benar hanya mencintai Corrie dan tak pernah ada sedikitpun menaruh hati pada Rapiah. Tertulis dalam penggalan surat itu, Hanafi memutuskan hubungan suami-istri dengan Rapiah, dan memulangkan pada ibundanya. Tegasnya lagi Hanafi pun mengutarakan perasaannya dala surat tersebut. Hal itu dapat terlihat dalam kutipan sebagai berikut.

"Janganlah anakanda mengumpat-umpat juga kepada Rapiah, sebab sebenarnya bukan salahnya maka ia serupa itu. Tapi sebaliknya janganlah pula anakanda diberi jalan terus mendurhaka kepada Ibu. Segala bencana dan perasaan yang anak anda tanggung selama mengikat diri pada seorang istri pemberian ibu itu tidaklah akan anakanda bangkit-bangkit lagi, melainkan ibu sajalah yang 
akan memakluminya.Oleh karena itu,Ibu, izinkanlah anakanda buat memulangkan barang yang ibu berikan itu ke tangan Ibu sendiri.

Sia-sia bagi Rapiah menanti-nantikan pulangku, dan sekali-kali janganlah ia bercita-cita hendak datang ke Betawi" (hlm. 134)

Kutipan dari penggalan surat tersebut menegaskan bahwasanya perasaan terpaksa Hanafi menikahi Rapiah sematamata karena ibundanya dan bukan berlandaskan rasa cinta. Hanafi tentu tidak ingin terus berdosa pada ibundanya, namun Hanafi pula tak bisa meneruskan hidup dengan Rapiah perempuan yang tak dirasakannya cinta sedikitpun. Hanafi bermaksud meminta izin untuk mengembalikan Rapiah pada ibundanya dan berpesan pada Rapiah agar tak menunggu-nunggu dirinya.

Setelah dua tahun menikah Corrie dan Hanafi menempuh jalan yang penuh rintangan. Hanafi yang mempunyai ego menginginkan Corrie sepenuhnya dan bertingkah seperti dulu, sebab ia merasakan adanya perubahan pada diri Corrie.

Ego Hanafi pun jelas pada saat pertikaian akibat menaruh cemburu pada Corrie yang selalu didatangi wanita tua yang pekerjaannya sebagai 'mak comblang' setiap hari. Kemuncanya, Hanafi menjelaskan tentang pengorbanannya untuk Corrie. Hal tersebut dapat dilihat dalam kutipan sebagai berikut.

"Haruslah engkau menaruh kasihan kepada seorang lakilaki yang sudah membuang diri ini!” (hlm. 182)

\section{c. Superego}

Meskipun Hanafi amat mencintai Corrie dan tak ada wanita lain di pikirannya melainkan dia, terlebih perempuan yang diberikan ibundanya yang tak sama sekali ia menaruh hati. Tetapi, Hanafi pun tak ingin berdosa dan sayang pada ibundanya. Ibundanya menginginkan Hanafi memperistri Rapiah sebagai balas budi dan bayar piutang, terlebih Hanafi sudah cukup berusia dan terus dalam duka selepas Corrie memutuskan hubungan dengannya. Hal itu terlihat dalam kutipan sebagai berikut.

"Lamalah Hanafi termenung dan memicingkan matanya, memikir-mikirkan segala yang dituturkan ibunya itu. Yabagi Hanafi 'kesatu' sampai 'kelima' itu 'omong kosong'belaka. Kalau itu saja kepentingannya, sukalah ia 
tidak beristri, tapi yang penghabisan itu! Bertimbang tanda bertunangan ayah si gadis sudah merugi!’' (hlm. 66)

Superego Hanafi pun nampak, kala ia menyadari kesalahannya, dan ia pun dengan segera pergi ke Semarang untuk menemui Corrie untuk memintanya kembali hidup bersamanya. Hal itu dapat terlihat dalam kutipan sebagai berikut.

"Ke Semarang Hanafi telah mengambil keputusan dalam hatinya hendak berangkat ke Semarang, mendapatkan Corrie. Jika ia tidak diterima oleh istrinya- wallahu alam! Apa yang akan terjadi atas dirinya. Hanafi pun tidak tahu. Yang diketahuinya hanyalah bahwa keadaan serupa itu tak kuat lagi ia menahan. Jika diperturutkan hatinya, boleh jadi akan gilalah ia" (hlm. 225)

Kutipan tersebut menjelaskan kesadaran Hanafi akan hal yang diperbuatnya sungguh membuat Corrie terluka hingga Corrie melarikan diri ke Semarang. Hanafi yang setelah menyadari kesalahannya bergegaslah ia ke Semarang untuk menemui dan meminta maaf serta ingin meminta Corrie hidup bersamanya.

"Setiap orang tiadalah hidup buat cita-cita saja, tapi terutama buat kewajiban. Kewajiban pada ibunya, kewajiban pada anak istrinya" (hlm. 270)

Kutipan tersebut nampaklah jelas penyesalan Hanafi akan apa yang diperbuatnya pada Rapiah istrinya, Syafei putranya, dan ibundanya. Hingga ia sampai berbuat nekad karena merasa sudah luput dirinya dengan kesalahan dan dosa.

Tokoh utama perempuan dalam novel Salah Asuhan yaitu Corrie, memiliki psikoanalisis sebagai berikut.

a.

Aspek id yang terdapat dalam tokoh Corrie muncul sejak Hanafi mencium punggung tangannya. Corrie langsung menanyakan perasaannya pada Ayahnya Tn. Du Bussee mengenai sesuatu yang mungkin saja terjadi padanya. Hal tersebut terlihat dalam kutipan di bawah ini.

"Pa, apakah alangan perkawinan orang Barat dengan Orang Timur?" (hlm. 15) 
Kutipan di sana dimaksudkan bagaimana halangan jika perkawinan dilansgungkan antara Corrie dan Hanafi. Di sanalah terlihat bahwa Corrie mulai menaruh hati pada Hanafi. Hal-hal lain semakin terlihat pada saat Corrie bingung akan perasaannya saat tertidur nyenyak di mana Hanafi terus membayang dan terus mengira-ngira dengan setiap strip pada kelambu di ranjang tidurnya. Corrie sebenarnya tidak menaruh harap bila Hanafi akan memperistri dirinya, melainkan hanya saudara tua saja.

"Dalam berbaring itu hebatlah peramukan pikiran dengan perasaan Corrie, berasalah sekarang cinta Hanafi tidak dapat ditolaknya, selama ia berhampiran dengan laki-laki itu.Pandang Hanafi, suaranya, tingkah lakunya, jika ia sedang menyatakan cintanya, semuanya sungguh membawa hanyut pada Corrie. Itu tak disangkal lagi. Tapi Corrie tidak suka akan menjadi istrinya, karena tidak boleh!” (hlm. 49)

Kutipan di atas jelas menunjukkan perasaan Corrie masa itu, id menaruh hati pada Hanafi, namun ia tak mungkin mau diperistri karena banyaknya halangan dan keburukan yang pasti menimpanya di antara kawin silang, terlebih nona Barat dengan tuan Timur.

b.

o

Sebagai manusia biasa Corrie pun memiliki ego dalam dirinya. Ego tersebut muncul ketika Corrie mengirimkan sepucuk surat yang dialamatkan pada Hanafi dengan harapan Hanafi tak lagi menulis surat untuknya. Hal tersebut terlihat dalam kutipan di bawah ini.

"Sahabatku Hanafi,

Seorang kawanku pada masa ini ada di Bukittinggi, dan ia ingin berjumpa dengan aku. Boleh jadi kami dari sana akan berangkat ke Padang atau Lubuklinggau itu belum tentu, karena nona sahabatku itu mempunyai keluarga di kedua tempat itu, sedang ia bermaksud hendak membawaku melihat negeri-negeri lain. Bila rasanya aku akan kembali ke Solok, belumlah dapat ditentukan.

Kalau engkau menerima surat ini, tentulah aku sudah di kereta api" (hlm. 50) 
Kutipan tersebut menunjukkan bahwa memaksakan kehendak perasaannya yang ingin menepi sejenak untuk tidak memikirkan Hanafi dan menjauhi Hanafi

Ego Corrie pun semakin menjadi-jadi ia menceritakan semuanya pada Hanafi tentang kondisinya saat ini. Hal itu dapat terlihat dalam kutipan sebagai berikut.

"Membuang diri? Seorang nona Eropa bersuamikan orang Melayu- itu namanya membuang diri, Meneer Han! Lihatlah keadaanku sekarang. Badanku rusak, uangku habis, bangsaku melihat kepadaku sebagai kepada najis, itulah namanya 'membuang diri'. Tapi Meneer Han rupanya berasa lebih rugi dari aku? Oh, oh!' (hlm. 182)

Kutipan tersebut jelaslah dipaparkan kondisi Corrie yang tak dianggap lagi oleh bangsanya. Corrie memperlihatkan kondisi tubuhnya yang sudah tak sebaik dulu, hartanya habis dan segalanya serba berkekurangan. Ia pun kesal terhadap Hanafi yang menimpalnya yang seolah-olah Hanafi yang lebih menderita. Corrie begitu menderita, Corrie begitu merugi, Corrie begitu merasakan akibat dari larangan perkawinan berlainan bangsa, apalagi seorang nona yang menikah dengan tuan pribumi. Nyatalah bahwasanya Corrie semakin diasingkan dan tersisihkan dari bangsanya sendiri dan membuatnya menyendiri dan penuh penderitaan.

c.

Su

\section{perego}

Meskipun Corrie memiliki kewajiban untuk menolak Hanafi dan tak ingin dengan Hanafi, namun Corrie juga pada dasarnya mencintai Hanafi. Hal tersebut nampak saat ia mengharapkan Hanafi untuk selalu bersamanya. Hal tersebut dapat terlihat dalam kutipan sebagai berikut.

"Alangkah senang hatiku, Hanafi, bila engkau mempunyai kendaraan berupa itu pula. Pukul tujuh aku sudah dari Gang Pasar Baru, pukul setengah sembilan mesti ada di asrama-sejam setengah kita boleh pesiar sekelilingi kota Betawi! Apakah tidak senang?" (hlm. 107)

Dari kutipan tersebut jelaslah perasaan yang sebenarnya dari Corrie akan Hanafi, yang mana Corrie menginginkan Hanafi selalu bersama-sama dengannya di mana di sana Corrie mengumpamakan sekadar berkeliling kota Betawi. 


\section{Psikoanalisis Tokoh dalam Novel Layla Majnun Karya Syaikh Nizami}

Tokoh utama laki-laki dalam novel Layla Majnun yaitu Qays, memiliki psikoanalisis sebagai berikut.

\section{a. Id}

"Gadis itu memiliki kecantikan yang luar biasa yang membuat Qays dan bocah-bocah lelaki lainnya langsung terpukau” (hlm. 12)

Qays secara tidak sadar sudah jatuh cinta dengan tokoh utama perempuan, Layla. Ia jatuh cinta karena pesona kecantikan yang dimiliki Layla begitu terpancar sampai mampu membuat para laki-laki terpikat.

“...perasaan Qaysmuda jauh lebih dalam dibandingkan teman-temannya. Ia telah tenggelam dalam lautan cinta bahkan sebelum ia mengenal arti cinta yang sesungguhnya. Ia telah memberikan hatinya kepada sang gadis bahkan sebelum ia menyadari apa sebenarnya yang ia berikan" (hlm. 12)

Dalam kutipan di atas, menggambarkan Qays yang tanpa sadar sudah benar-benar jatuh cinta kepada Layla. Perasaannya tersebut bahkan tidak main-main seperti laki-laki lainnya.

b. Ego

"Semakin lama penderitaannya, semakin pula ia menjadi sosok yang diteriakkan semua orang kepadanya: Majnun, si orang gila" (hlm. 19)

"Suatu hari ia berjalan seolah tak sadarkan diri; keesokan harinya ia bertingkah bak seorang pemabuk, berjalan terseok-seok, menangis terisak-isak dan merintih-rintih" (hlm. 20)

Dari kedua kutipan di atas, menggambarkan sosok Qays yang sudah dijuluki majnun, Tidak ada lagi sosok Qays, laki-laki tampan dan cerdas itu. Qays memilih menjadi majnun, ketika cintanya kepada Layla yang begitu besar, telah ditentang oleh orang tua Layla. 
"Majnun sadar bahwa maksud teman-temannya baik, namun mereka tak mengetahui seberapa besar sesungguhnya cintanya untuk Layla: mereka-mereka yang tak pernah merasakan rasa sakit seperti ini takkan dapat memahaminya, apalagi menasihatinya." (hlm. 31)

"Pada akhirnya, Majnun tak lagi dapat bergaul dengan siapa pun. Karena itulah ia meninggalkan orang tuanya, keluarganya serta teman-temannya dan melarikan diri ke tengah gurun, tanpa mengetahui ke mana arah tujuannya dan apa yang akan dilakukannya" (hlm. 31)

Kedua kutipan tersebut menjelaskan bahwa Qays sudah terperangkap dalam cinta yang begitu besar kepada Layla. Sebanyak apapun nasihat yang diterimanya, tidak membuatnya mengubah keras kepalanya kerena perasaannya terhadap Layla sudah tertancap dalam hatinya. Ia bahkan rela meninggalkan semuanya, untuk berkelana tanpa tujuan.

\section{c. Superego}

"Ya Allah, sang Pencipta segalanya! Kumohon kepadaMu, ringankanlah beban hidupku ini! Bebaskanlah aku dan biarkan aku melangkah menyusul kekasihku! Lepaskanlah ikatan rantai yang mengikatku pada dunia yang kejam ini dan biarkan aku terbang!" (hlm. 228)

Pada kutipan di atas, Qays berdoa di samping makam Layla, meminta agar ia dijemput oleh kematian untuk menyusul pujaan hatinya, Layla. Kutipan tersebut memberikan gambaran bahwa Qays tidak pernah berubah dalam mencintai Layla sampai kepada kematian Layla.

Tokoh utama perempuan dalam novel Layla Majnun yaitu Layla, memiliki psikoanalisis sebagai berikut.

a. Id

"Namun Qays tidak sendirian karena Layla pun merasakan hal yang sama. Api telah menyala dalam kedua hati mereka, dan api itu saling menerangi satu sama lain" (hlm. 12)

Kutipan di atas, menunjukkan tokoh Layla, yang secara tidak sadar juga merasakan jatuh cinta kepada Qays. Keduanya 
memiiki perasaan saling mencintai.

b. Ego

"Sedari matahari terbit hingga terbenam, ia terus mencoba mencari kekasihnya Majnun, secara rahasia. Lalu, di tengah malam, saat semua orang tidur terelap, ia akan memanggil-manggil nama kekasihnya dalam desahan. Airmata tak pernah berhenti mengalir di pipinya, ia hanya tertawa untuk menyembunyikan kesedihannya" (hlm. 56)

"Sepanjang hari ia merana dalam diam, berpura-pura tersenyum dan tertawa, berusaha menanggapi jika diajak bicara, namun kala malam tia ia segara berbaring di atas tempat tidurnya dan menangis hingga air matanya tak lagi dapat keluar" (hlm. 109)

Kedua kutipan di atas, menggambarkan ego dari sosok Layla yang memilih mencintai Qays dalam diam. Karena pertentangan cintanya, Layla memilih berpura-pura bahagia walaupun setiap malam ia habiskan dengan menangis.

"Aku bersumpah demi Allah jika kau mencoba melakukannya sekali lagi, kau akan menyesalinya seumur hidup. Aku telah bersumpah kepada sang Pencipta bahwa aku takkan menyerahkan diriku kepadamu. Kau boleh menggorok leherku dengan pedangmu, jika kau mau, tapi kau takkan dapat memaksaku." (hlm. 116)

Kutipan di atas juga merupakan ego yang dikeluarkan oleh tokoh Layla. Karena ia memilih mencintai Qays dalam diam, ia tidak membiarkan suaminya pun menyentuh dirinya. Itu membuktikan bahwa hati Layla hanya untuk Qays.

\section{c. Superego}

"Memang benar bahwa Layla tak pernah mencintai pria itu, namun Ibn Salam pernah menjadi suaminya dan tentunya ia berhak mendapatkan belas kasih dari Layla. Dan Layla memang berbelas kasih kepadanya..." (hlm. 217)

Superego yang ditampilkan oleh tokoh Layla dalam kutipan di atas, yaitu Layla memilih tetap berbelas kasih ketika suaminya 
meninggal dunia. Walaupun Layla tidak mencintai Ibn Salam, ia melakukan itu karena Ibn Salam pernah menjadi suaminya.

"Katakan kepadanya: Ketika Layla meninggakan dunia ini, ia pergi dengan menyebutkan namamu. Kata-kata yang diucapkannya hanya berkaitan denganmu; dalam kematian pun ia masih tetap setia kepadamu. Ia telah berbagi kesedihanmu di dunia ini dan kini ia telah membawanya sebagai bekal perjalanannya." (hlm. 222)

Kutipan di atas, merupakan superego lainnya yang ditampilkan oleh tokoh Layla. Saat detik-detik sebelum Layla meninggal dunia, ia memiliki pesan kepada Qays yang disampaikan melalui Ibunda Layla, bahwa Layla tetap mencintai Qays sampai kematian mendatanginya. Layla tidak menyesal telah mencintai Qays dalam diam dan terus menangis karena itu.

Tabel hasil perbandingan tokoh utama laki-laki

\begin{tabular}{|c|l|l|l|}
\hline No. & $\begin{array}{l}\text { Aspek } \\
\text { Psikoanalisis }\end{array}$ & Salah Asuhan & Layla Majnun \\
\hline 1 & Id & Mencintai Corrie & Mencintai Layla \\
\hline 2 & Ego & $\begin{array}{l}\text { Menolak } \\
\text { perjodohan dan } \\
\text { Menikah dengan } \\
\text { Corrie }\end{array}$ & $\begin{array}{l}\text { Tetap mencintai } \\
\text { Layla sampai } \\
\text { menjadi gila }\end{array}$ \\
\hline 3 & Superego & $\begin{array}{l}\text { Mendampingi } \\
\text { Corrie di akhir } \\
\text { hayat hidupnya }\end{array}$ & $\begin{array}{l}\text { Mendampingi } \\
\text { Layla di akhir } \\
\text { hayat hidupnya }\end{array}$ \\
\hline
\end{tabular}

Tabel hasil perbandingan tokoh utama perempuan

\begin{tabular}{|c|l|l|l|}
\hline No. & $\begin{array}{l}\text { Aspek } \\
\text { Psikoanalisis }\end{array}$ & Salah Asuhan & Layla Majnun \\
\hline 1 & Id & Mencintai Hanafi & Mencintai Qays \\
\hline 2 & Ego & $\begin{array}{l}\text { Menikah dengan } \\
\text { Hanafi }\end{array}$ & $\begin{array}{l}\text { Tetap mencintai } \\
\text { Qays dalam diam }\end{array}$ \\
\hline 3 & Superego & $\begin{array}{l}\text { Pergi } \\
\text { Meninggalkan } \\
\text { Hanafi }\end{array}$ & $\begin{array}{l}\text { Jatuh sakit dan } \\
\text { meninggal dunia } \\
\text { karena }\end{array}$ \\
\hline
\end{tabular}




\begin{tabular}{|l|l|l|}
\hline & & memikirkan \\
& Qays \\
\hline
\end{tabular}

\section{SIMPULAN}

Penelitian ini dilaksanakan untuk membandingkan karya sastra yang lahir di Indonesia dengan karya sastra yang lahir di luar negara Indonesia menggunakan kajian psikologi sastra oleh teori psikoanalisis Freud, berkaitan dengan id, ego, dan superego yang dimiliki oleh tokoh utama laki-laki dan tokoh utama perempuan pada novel Salah Asuhan karya Abdoel Moeis berasal dari tanah Sumatera, Indonesia dibandingkan dengan novel Layla Majnun karya Syaikh Nizami berasal dari Persia, yang saat ini sudah menjadi negara Iran. Hasil analisis kepribadian pada tokoh dari kedua novel memiiki beberapa kesamaan perilaku dan tindakan yang dialami tokoh utama, dengan hal yang membedakannya ialah latar belakang budaya dan zaman yang berbeda dari kedua novel tersebut. Sehingga kedua novel dengan budaya yang berbeda mampu menciptakan sebuah karya sastra dengan kemiripan cerita dan karakter tokoh yang dominan sama.

\section{DAFTAR PUSTAKA}

Endraswaa, Suwardi. 2008. Metode Penelitian Psikologi Sasta: Teori, Langkah, dan Penerapannya. Yogyakata: MedPress.

Endraswara, Suwardi. 2014. Metodologi Penelitian Sastra Bandingan. Jakarta: Wedatama Widya Sastra.

Kutha Ratna, Nyoman. 2015. Teori, Metode, dan Teknik Penelitian Sastra. Yogyakarta: Pustaka Pelajar.
Minderop, Albertine. 2011. Psikologi Sastra: Karya, Metode, Teori, dan Contoh Kasus. Jakarta: Yayasan Pustaka Obor Indonesia. Moeis, Abdoel. 2000. Salah Asuhan. Balai Pustaka.

Nizami, 2014. Layla Majnun. Yogyakarta: Narasi.

Rosidi, Ajip. 2017. Ikhtisar Sejarah Sastra Indonesia. Bandung: Pustaka Jaya. 